ISSN: 2162-3104 Print/ ISSN: 2166-3750 Online

Volume 8, Issue 2 (2018), pp. 769-794

(C) Journal of International Students

http://jistudents.org/

doi: 10.5281/zenodo.1250379

\title{
Understanding East Asian Graduate Students' Socio-cultural and Psychological Adjustment in a U.S. Midwestern University
}

\author{
Yiying Xiong \\ Ohio University, United States \\ Yuchun Zhou \\ Ohio University, United States
}

\begin{abstract}
In this study, we explore East Asian graduate students' socio-cultural and psychological adjustment in a U.S. Midwestern University. Eight participants were interviewed about their acculturation challenges as well as their effective coping strategies. Data were analyzed using open-coding techniques and five themes emerged: three themes summarized the challenges, including challenges due to cultural differences, lack of support in a foreign environment, and financial stress; and the other two themes that described the coping strategies were utilizing external resources and developing self-adjustment strategies.
\end{abstract}

Keywords: acculturation, East Asian graduate students in the U.S., psychological adjustment, socio-cultural adjustment

In recent years, an increasing number of international graduate students have enrolled in U.S. higher education. Between academic year 2010/11 and $2016 / 17$, the percentage of international graduate students increased by $32 \%$, from 296,574 to 391,124 (Institute of International Education [IIE], 2017). Those students were reported to experience financial stress, 
assistantship, jobs, school work, and having multiple roles (Oswalt \& Riddock, 2007), and have to deal with various challenges beyond academics, such as psychological adjustment and social behavioral adjustments to the U.S. academics (Zhou, Frey \& Bang, 2011).

Among all groups of graduate students, East Asian international students represented the largest percentage $(43 \%)$ of international students in the U.S. (IIE, 2017). However, they were also the most challenged group to acculturate to the U.S. graduate schools due to Eastern-Western cultural differences ( $\mathrm{Li}$, Wang, \& Xiao, 2014). Thus, this study selected this group as the target population for investigation.

In the previous literature on East Asian students' acculturation, researchers mainly focused on students' adjustment in general or just sociocultural adjustment; few articles associated the acculturation issues with students' psychological adjustment (Zhang \& Goodson, 2011). In this paper, to seek a more complete picture of those students' acculturation, we explored both socio-cultural and psychological adjustments. Socio-cultural adjustment described the ability to fit in a new culture, to attain appropriate skills and to negotiate interactive areas of the host culture; while psychological adjustment indicated psychological wellbeing in the above acculturation process (Ward \& Kennedy, 1996). Previous literature indicated that the major socio-cultural adjustment faced by East Asian international students included acculturative stress, language barrier, perceived discrimination and other issues (Li et al., 2014). Students also suffered some psychological problems such as depression and anxiety (Han, Han, Luo, Jacobs, \& Jean-Baptiste, 2013). Despite the difference between psychological and socio-cultural adjustment, they were interrelated domains (Ward \& Kennedy, 1996). However, few details were reported regarding how the two types of challenges interact with each other and resulted in additional difficulty in acculturation. Moreover, little research has discussed about the strategies that East Asian graduate students have utilized to cope with those challenges (Park, Lee, Choi, \& Zepernick, 2017).

Therefore, the purpose of this qualitative study was to describe the acculturation of East Asian graduate students in a Midwestern university from both socio-cultural and psychological perspectives. For the purposes of this research, acculturation was defined as "those phenomenon which results when groups of individuals having different cultures come into continuous first-hand contact, with subsequent changes in the original culture patterns of either or both groups" (Redfield, Linton, \& Herskovits, 1936, p. 145). An 
international student was defined as "an individual who is enrolled for credit at an accredited higher education institution in the U.S. on a temporary visa, and who is not an immigrant (permanent resident with an I-51 or Green Card), or an undocumented immigrant, or a refugee" (United Nations Educational, Scientific and Cultural Organization, 2006, para. 1). Two research questions were addressed in the study:

1. What challenges did East Asian graduate students face in the process of socio-cultural and psychological acculturation to the U.S. graduate education?

2. What strategies were adopted by these students to cope with the challenges related to socio-cultural and psychological adjustments?

The significance of the study consisted of the following: (a) providing educators with the details of East Asian students' behaviors and mental well-beings in the process of acculturation, (b) enhancing faculty and domestic students' understanding of East Asian graduate students' challenges to adapt to the U.S. graduate education , (c) generating a complete picture of acculturation strategies and suggestions for the current and future East Asian graduate students in the U.S., and (d) helping the students affairs to improve their services and support for this group of students.

\section{LITERATURE REVIEW}

\section{Acculturation and Sojourner}

According to Berry's definition, acculturation was bi-dimensional, that people were adjusting to the host culture in some ways but maintaining their original identity in other ways (Berry, Poortinga, Breugelmans, Chasiotis, \& Sam, 2011). In other words, "change can take place along two independent dimensions, one dimension being the maintenance or loss of original culture and the other being participation in, or adaptation of, aspects of the new culture" (Berry et al., 2011, p. 309). Four different acculturation strategies were proposed with the two dimensions: assimilation, integration, separation, and marginalization (Berry et al., 2011). Moreover, five general types of acculturation groups were categorized by their degree of voluntariness, permanence of contact, and movement: ethnocultural groups, indigenous people, immigrants, refugees or asylum seekers, and sojourners 
(Berry et al., 2011). The first four groups of people were typically intended to stay longer in the host country voluntarily or involuntarily, while sojourners were those who voluntarily travelled to a new place for a limited period to accomplish a certain purpose (Berry et al., 2011). By this definition, East Asian graduate students belonged to the sojourners group. Kim (1988) described sojourners' acculturation process as a back-and-forth movement within a stress adaptation dialect, like a "draw-back-to-leap" or "two steps forward and one step back" (p. 101-102).

As a result of the process, two kinds of adjustment came with acculturation: psychological adjustment and socio-cultural adjustment (Ward \& Kennedy, 1996). Psychological adjustment referred to psychological wellbeing or satisfaction that was impacted by personality, life changes, coping styles and social support (Ward \& Kennedy, 1996). While socio-cultural adjustment referred to the ability to function well in the new culture, to attain appropriate skills and to negotiate interactive areas of the host culture, and it is measured by "the amount of difficulties experienced in the management of everyday social situation in the host culture" (Ward \& Kennedy, 1996, p. 291). Moreover, the socio-cultural adjustment was influenced by factors about "cultural learning and social skills acquisition", such as length of residence in the host country, amount of interaction, language fluency, identification with the host culture, cultural distance, and acculturation strategies (Ward \& Kennedy, 1999, p. 661). Despite the differences between psychological and socio-cultural adjustment, they were interrelated domains (Ward \& Kennedy, 1996). Some of the common factors that impacted both psychological and socio-cultural adjustments were language fluency and length of residence (Zhang \& Goodson, 2011).

\section{Acculturation of East Asian international Students}

East Asian international students included those from China, Japan, North South, and South Korea, who shared the ethical philosophy of Confucius, Buddhism, and historically a common writing system (Reischauer, 1974). Given the tremendous cultural, ethnic and racial variation within Asia, four subgroups (i.e. East Asia, South Asia, Southeast Asia, and Pacific islanders) were usually found in literature (Baruth \& Manning, 2007). Among international students who come from Asia in the U.S., East Asian international students represented the largest population (IIE, 2017). However, they were reported to be more challenged in 
acculturating to the U.S. culture than other groups of international students in the U.S. (Li et al., 2014).

Psychological adjustment. It was reported that international students, especially those from East Asia, were at greater risk for various mental health issues because of adjustment issues and stresses (Ra \& Trusty, 2017). For example, Han et.al (2013) reported that the percentage of Chinese international students who had depression and anxiety symptoms were much higher than that of general students in American universities. Numbers of factors were related to their psychological adjustment, such as stresses, social support, language proficiency, length of residence, acculturation, personality, and attitude towards psychological services (Li et al., 2014; Zhang \& Goodson, 2011).

Socio-cultural adjustment. Although East Asian students stated that they sought support from American friends and professors, their primary social support came from their parents and the peer-based network of other international students in the U.S. (Bertram, Poulakis, Elsasser, \& Kumar, 2014). Moreover, the interactions with Americans, whether it happened in daily life or academic, were difficult for Asian international students because of the different social norms and language problems (Liu, 2009; Mori, 2000). For example, Asian international students thought the friendship with Americans was superficial because of the individualist belief in friendship of Americans (Ra \& Trusty, 2017). Liu (2009) stated that a lack of English proficiency of Asian international students decreased the quality of their communication with Americans.

For most Asian international students, the main motivation to come to the U.S was to search for a better higher education (Liu, 2009). However, great differences between the East Asian and the U.S. academic systems exist, including teaching methods, studying styles, and evaluation systems. Most international graduate students were satisfied with American higher education (Zhou et al., 2007), but the biggest obstacle East Asian graduate students faced in study was English language (Zhang \& Goodson, 2011). While reading and writing were challenges to them, some also reported difficulty with class activities, oral participation, and following the lectures (Zhang \& Goodson, 2011). The difficulties to adjust to the U.S. academic system are involved with Asian students' socio-cultural adjustment process as they need to spend large amount of time and effort to adjust to the difficulties in a daily basis. That said, their life pattern and life quality are greatly changed by dealing with the acculturation difficulties. 


\section{Coping Strategies}

Park et al. (2017) reported a lack of research on East Asian international students' coping strategies. In a limited number of literature, it was found that establishing social and cultural connections in real life or on the internet helped international students better adapt to the new life (Ra \& Trusty, 2017; Ye, 2005). The academic and social interactions with American peers relieved negative feelings of Asian international students such as homesickness (Zhou et al., 2011). Moreover, they also benefited from some physical activities (Brunette, Lariviere, Schinke, Xing, \& Pickard, 2011). The use of forbearance was another coping strategy (Wei, Liao, Heppner, Chao, \& Ku, 2012).

\section{RESEARCH METHOD}

\section{Research Design}

The purpose of this study was to describe the socio-cultural and psychological adjustments of East Asian graduate students in a Midwestern university. Qualitative research methods were selected in this study because they help with the exploration of participants' experience and perspectives. By hearing the participants' description of their behaviors and views in a natural setting, the researchers can explore and understand a phenomenon in depth (Lindlof \& Taylor, 2010). In the past, few researchers have used qualitative methods to study East Asian international graduate students.

\section{Participants}

East Asian graduate students in a Midwestern university in the U.S. were purposefully selected as the participants. Multiple sampling strategies were used, including criteria and snowball sampling. The demographic information of all participants was shown in the following table.

\section{Data Collection Procedure}

Before data collection, the investigators of the study obtained the approval from the Institutional Review Board (IRB) at their institution. Multiple sampling strategies were used to select participants. For Chinese graduates, the investigators selected participants by using a QQ group named "the Chinese international students at the OU," which was a widely used social media among Chinese. The investigators posted an advertisement in the group for a week to recruit Chinese graduate students. 
Three doctoral students contacted the investigators and were willing to share their experience. Then snowball sampling strategy was used to further recruit participants in the study. In specific, one participant referred another student from Mainland China, one from South Korea and one from Taiwan. Then the South Korean participant referred another one from the same country and one from Japan. At last, eight participants from Mainland China, Taiwan, South Korea, and Japan were included in the study.

Table 1. The Demographic Information of Participants

\begin{tabular}{|c|c|c|c|c|c|}
\hline Name & Gender & Age & $\begin{array}{l}\text { Place of } \\
\text { Origin }\end{array}$ & Major & $\begin{array}{l}\text { Educational } \\
\text { Level }\end{array}$ \\
\hline LQN & Female & 25 & $\begin{array}{l}\text { Mainland } \\
\text { China }\end{array}$ & Communication & Doctoral \\
\hline $\mathrm{CY}$ & Male & 23 & $\begin{array}{l}\text { Mainland } \\
\text { China }\end{array}$ & Chemistry & Doctoral \\
\hline SMW & Male & 40 & $\begin{array}{l}\text { Mainland } \\
\text { China }\end{array}$ & Higher Education & Doctoral \\
\hline $\mathrm{HH}$ & Female & 25 & South Korea & Communication & Doctoral \\
\hline $\mathrm{ZC}$ & Male & 24 & $\begin{array}{l}\text { Mainland } \\
\text { China }\end{array}$ & Mathematics & Master \\
\hline LHT & Male & 30 & Taiwan & $\begin{array}{l}\text { Counselor } \\
\text { Education }\end{array}$ & Doctoral \\
\hline M & Female & 25 & Japan & Athletic Training & Master \\
\hline $\mathrm{SC}$ & Male & 41 & South Korea & $\begin{array}{l}\text { Interdisciplinary } \\
\text { Art }\end{array}$ & Doctoral \\
\hline
\end{tabular}

After recruiting participants, the investigators made an appointment with each of them to conduct the interviews. The principal investigator (PI) did face to face interviews with each participant by using a semi-structured interview protocol. The protocol was designed based on the research questions. It explored participants' experiences and perspectives of studying and living in the U.S. Interview questions included: "What kind of difficulties in daily life and study you have met so far?" and "How have you solved these problems?" During the interviews, probe questions were added according to participants' responses. All the interviews were conducted in a school office individually. Signatures were obtained from participants before interviews. All interviews lasted about 40-60 minutes and were recorded with a digital recorder. All the interviews were conducted in English, except for the interviews with Chinese participants, which were conducted in Chinese. 


\section{Data Analysis}

After each interview, the investigators transcribed the interview in a timely manner to maximize the memory of the conversation. For data analysis, the investigators analyzed data using open coding techniques. Open coding included reading raw data and segmenting them into categories of information (Strauss \& Corbin, 1990). Accordingly, the investigators started with reading through all the transcripts to grasp the overall understanding and separated the relevant information about acculturation into pieces. Then the investigators summarized these information segments using short phrases, which were called codes. As a result, approximately nine codes were generated from the interview data. The investigators further grouped the similar codes into categories and summarized the categories to generate themes. For example, the theme of challenges due to cultural differences summarized several codes, including communication problems due to language issues, involvement problems due to socio-cultural differences, and difficulties in learning due to academic differences. The whole coding process was conducted using the program of MaxQDA10, which is a qualitative data analysis software.

\section{Validation Strategies}

Several validation strategies were used in the study. First, member checking was used with all participants to ensure the accuracy of the transcripts. The transcripts were sent to the participants for member checking. The participants reported no misrepresentations of their answers. Second, intercoder agreement was used to check the consistency of the generated themes and codes. A doctoral student with experience in qualitative research was invited to code the transcripts. As a result, $80 \%$ of the codes were similar in meaning. Third, peer debriefing was used for the entire research process. The research process was reviewed and discussed by a research methodology professor and a few graduates major in counseling. Last, the PI kept reflecting on the influence of her experience on the research as a Chinese doctoral student in the U.S. whose major is counselor education. On one hand, the PI has been experiencing acculturation. Thus, the PI was not only empathic with the experience of her participants but also understood those experiences well. On the other hand, the PI has learned to respect the experience or opinions of each person from a counselor perspective. These background and attitudes helped her to build up a rapport 
with the participants, which also helped with the reliability of data collection and coding.

\section{FINDINGS}

Five themes were generated to answer the research questions of what challenges were in socio-cultural and psychological adjustment and what strategies were used to cope with those challenges. Specifically, three themes summarized the challenges, including challenges due to cultural differences, lack of support in a foreign environment, and financial stress. The other two themes described the coping strategies: utilizing external resources, and developing self-adjustment strategies (see Appendix A).

\section{Theme 1: Challenges due to Cultural Differences}

The major acculturation challenges for East Asian international students included communication problems and involvement problems due to language barriers, socio-cultural differences, and academic differences. These problems also influenced students' mental health, which made their adaptation process more challenging than they could expect.

Communication problems due to language issues. Almost all participants experienced language issues which heavily impacted their daily communication at school, such as difficulties to express themselves and difficulties to understand others. For example, CY said that his communication with other native students out of class was limited to daily greetings because he did not feel comfortable enough to engage in a longer conversation due to his limited English speaking.

Besides the challenges out of class communication, students also had problems with in-class communication due to language barriers. For instance, CY felt confused about his classmates' jokes in class because he did not understand the slang or cultural background. Moreover, the participants felt it was hard to follow their teachers' high-speed lectures. For example, SMW and LQN said that they were usually very quiet during class discussion because they had to think in Chinese and express the ideas in English, which took such a long time that the discussion topics had already progressed to other topics.

Language problems did not only impact participants' academic performance but also caused some mental issues like frustration and stress. When participants described the above challenges, they also expressed their 
frustration, anger, and stress due to ineffective communication with other people. Interviewee $\mathrm{HH}$ described typical situation that many international students have encountered: "I went to Verizon to change my phone plan and the staff was very rude. I was very angry but I even couldn't express my anger in English. I knew that I could say anything if I were in Korea. I just went out of the store and cried." In short, language barriers resulted in communication problems, which made East Asian students' life hard and unhappy in certain circumstances.

Involvement problems due to socio-cultural differences. Sociocultural differences, such as cultural beliefs, value and social behaviors between East Asians and Americans, served another barrier for students to get involved in the classroom and the society. For example, SMW stated that Chinese students were supposed to be modest and might be hesitant to give a speech. They only felt comfortable in talking when they had "a really comprehensive understanding," in contrast, American students were "bold" and "would speak whenever they got an idea." Therefore, East Asian students may not be able to get high grades due to the inadequate involvement in class discussion. Moreover, East Asian students generally believed in collectivism, which made them hard to acculturate to the American individualism culture. LQN said, "it was really hard to make real friends with Americans and be involved with them" as some of them are "so individual centered" and "not really caring about others." Furthermore, M stated that behavioral differences might also impede their involvement in America. She mentioned that Japanese seldom used " $\mathrm{hmm}$ " as it is very rude in her culture, "but lots of Americans said ' $\mathrm{hmm}$ ' when they did not understand me." She therefore didn't want to talk to anyone in her first year in the U.S.

Meanwhile, the above involvement problems also resulted in students' mental strains. Both ZC and LQN described their disappointment when they felt being "marginalized" during parties with American students. "I felt awful that I could not be involved in their conversation. I felt I was so lonely even though I was around with people" ZC said. Similarly, SMW felt he was "an outsider of the class" when he could not get involved in the class discussion.

Difficulties in learning due to academic differences. Academic difference between East Asian and American was another problem that affected East Asian international students' learning. Chinese and South Korean participants expressed their challenges when they adjusted to the 
teaching style in the U.S. CY said that he was painfully "immersed in the reading every day," for his professors required a large amount of readings for class discussion every week. This was very different from his previous learning experience in China where teachers covered readings requirements in class. Besides teaching style, $\mathrm{HH}$ and $\mathrm{ZC}$ mentioned that academic transition from master level in their home countries to the doctoral level in the U.S. was especially difficult. For instance, HH got her master's degree in South Korea, she felt the content in the doctoral program was "much deeper" and she was "stressed out" because of the transition. "Tired" and "overwhelmed" were the two major mental issues reported together with the above academic challenges. For instance, LHT shared his experience to adjust to the U.S. academic system and said, "I was so exhausted and I only could sleep for less than 6 hours a day in order to get my assignments done."

\section{Theme 2: Lack of Support in a Foreign Environment}

Besides the challenges due to cultural differences, lack of support made East Asian students' acculturation to the U.S. even worse. Participants generally reported that they always felt "frustration", "stressful" and "lonely" due to lack of adequate academic support and lack of emotional support.

Lack of academic support. Participants said that they felt a lack of adequate support from their departments, colleges, institution, and advisors. They expected that everything was pre-arranged by professors and schools, and they were not very used to looking for information themselves. For instance, SMW had no idea about what classes to register when he was in his first year, because there were no clear instructions for international graduate students in his department. Moreover, the lack of coordination between different departments raised confusion for international students as well. $\mathrm{M}$ told the investigators that "the officers in different departments gave me different rules about the same thing. I didn't know what to do, but just picked one and went with it." Besides lack of clear instruction, some students also complained that some regulations for international students were too strict and unnecessary. For example, $M$ had studied in the U.S. for four years and successfully obtained her undergraduate degree, however, she was still required to take TOFEL test as English requirement of her master's program. She argued that "I got my undergraduate degree in the U.S., which can already prove my English ability. Another TOFEL test takes me extra time to prepare and seems not very necessary." To her, the school office did 
not consider her individual situation for admission, which indicated lack of academic support for her.

Furthermore, lack of expected support from school increased the difficulty of East Asian students' life in American universities, and made them upset and frustrated, especially at the beginning of their acculturation process. For instance, M said, "the process stressed me out and I felt lots of frustration." Similarly, SMW used a metaphor to describe his feeling when he was at loss in his first year, "I was like a wild goose that lost his direction and was left behind by the group members."

Though some participants got help from their professors and colleagues, interaction experiences with professors were diverse. As reported by participants, some professors criticized their language proficiency more than their academic performance. For instance, LHT's professor almost failed LHT's practicum before knowing about him, just because the professor thought international students' English should not be good enough to be a counselor. HH's advisor always challenged her GA work products and asked her to do extra work beyond her GA hours. HH felt stressful because the extra GA work occupied her time of learning and personal life. She mentioned that "I knew criticizing on my work would help me to improve, but I wish that he could at least appreciate what I have done. The extra work for him occupied my personal time."

\section{Lack of Emotional Support}

Participants also reported difficulties in seeking emotional support when they felt depression in the acculturation process. SC told the investigators that he and the other two international students in his cohort desired to have some local friends that they could hang out but did not identify long-term American friends. LQN had the similar experience. She tried to approach her American colleagues for emotional consolation, but they were not very interested in her culture and hard to share ideas in depth. ZC's long-distance girlfriend broke up with him because they were lack of instant communication and emotional support for each other. ZC also suffered disappointment from his parents, "my parents did not understand what I am doing, but urged me to go to work."

Lack of emotional support from friends and family nearby, participants generally experienced mental difficulties, such as sense of loss, lonely, and even depression. LQN said that she was "so disappointed" when she found out it was hard to make "real friends" with Americans. ZC told us 
that he tried hard to be positive, but "I felt so depressed and stressful when my significant others did not understand my situation."

\section{Theme 3: Financial Stresses}

Financial stress was another challenge in participants' life in the U.S. They were usually worried about their financial assistantship, which influenced their daily life and academic studies. For instance, SC had to "downsize" his budget and look for jobs unrelated to his major when his department stopped his financial assistantship. Similarly, SMW had to work more than 20 hours a week to maintain his assistantship.

Financial stress caused negative emotions, such as "worries", "stress" and "overloaded", which resulted in East Asian international students' mental health problems. SC expressed his "worries" due to financial stress.

During the time, I could not get financial support, I felt stressful to meet my basic living needs. When I went to a grocery store, I sometimes think whether I could afford it next time, even some small things. It's hard to find jobs even though they are not even related to my major. When I was doing the job that was not related to my major, I warned myself that I should go back to my field as soon as possible, but I needed money. Then, I questioned myself what I am doing here in the U.S. Those questions made me crazy.

Similarly, LHT stated that financial issues made him feel "guilty" and "overloaded." He was 30 years old but still lived as a student without income. In his home country, most of his friends at his age have been working for a long time and become financially independent. In comparison, his family spent "a lot of money" and even borrowed debts for his oversea study. LHT said, "I felt so guilty to my girlfriend and family, I have no choice but to work harder to get a better future."

In summary, participants in the study not only described the specific challenges they have met both at school and out of class, they also went further to discuss their mental issues due to those challenges. Fortunately, when they tried hard to adjust to the new environment, they gradually developed some effective coping strategies to help themselves. 


\section{Theme 4: Utilizing External Resources}

\section{Resources for the Socio-Cultural Adjustment}

Participants actively sought help from different resources, such as advisors and professors, friends and family, and available resources in departments or university. Particularly, participants mentioned that help from their advisors and professors were extremely important because "the professors are someone who have the power to change our lives." LQN talked to her advisor about her problems due to language proficiency. After that, her advisor gave her special attention and support and often encouraged her in learning. Moreover, CY, M and HH thought "students from their home countries who had the same experience ahead" were very helpful with life support, such as "took them to open a bank account" and "told them where to buy food."

Additionally, resources in the university and departments were found to be helpful. Both SC and ZC mentioned the "regular meetings with their colleagues" was beneficial. SC said that "I even got my dissertation ideas from the meetings." ZC also stated "the conversation hour and pronunciation lab in one of my class are really helpful", because the conversation partners were very professional and helped him with learning.

\section{Resources for Psychological Adjustment}

The support from friends and peers not only helped with their social adjustment but also psychological adjustment. For instance, CY, M and $\mathrm{HH}$ mentioned that the international students from their home countries who were ahead of them provided them with emotional support. Several participants mentioned that friends and family back in their home countries gave them emotional support as well. For example, $M$ said that she skyped with her old friends in Japan almost every day in her first year in the U.S. and it helped to reduce her homesickness. ZC shared how he got emotional support from his regular meetings with teaching assistant (TA) group as following:

The weekly TA group was very supportive. I remember one time a TA said that he was so lonely. Another TA came out and shared her own feeling of loneliness as the oldest one in the group, and encouraged the TA that there were lots of people with the same feeling. I felt so involved and supported even though I was not the guy who came up with question. 
Some of other school resources, such as the counseling center, helped students' psychological adjustment as well. SMW mentioned that he went to the counseling center on campus and got support there, "At that time, I was really stressed out and I could not find anyone to talk with. I went there and shared my experience with them. It helped a lot!"

\section{Theme 5: Developing Self-Adjustment Strategies}

All eight participants described useful self-adjustment strategies to their psychological adjustment and behavioral adjustment.

\section{Psychological Self-Adjustment Strategies}

The participants mentioned they used multiple strategies to help with psychological stress, such as being positive to gain confidence, talking to themselves about the reasons for studying abroad, and utilizing forbearance. ZC, LHT and LQN all mentioned they tried different ways to encouraged themselves when they came across troubles. LQN hung a sticker in her room to encourage herself. ZC talked to himself that he would overcome whatever difficulties he met with. M, SC and LQN encouraged themselves by asking themselves "why did you choose to study abroad?" LQN told us that "sometimes I just wanted to quit, but my dream kept me to stay here." Forbearance was another useful copying strategy. HH stated, "When I felt that I couldn't do anything about my difficulties, I told myself that the only thing I can do is to let it go. It takes time and not easy, but that is the only way I can do."

Behavioral self-adjustment strategies. Besides the above psychological coping strategies, participants' life routines and daily behaviors were also changed to cope with challenges of acculturation. The typical behavioral strategy was to "work, work, and work." ZC said that "library is my second home." He usually worked very late in library to catch up with his coursework and to work for better grades.

Some participants forced themselves to reach out for help from their professors, friends and other resources. ZC said that "before I came here, I seldom reach out for help from my teachers. But now I look forward to meeting with my professors and ask for suggestions when I met difficulties." SMW made efforts to interact with different people, and he said that "I tried to catch every chance to know more about their culture and system because I know it is the best way to be involved in their society." 
Some participants went to gym every day for good health. For instance, SC did not have the running habit before coming to the U.S. Now, running is his daily routine. SC ran approximately 10 miles a day and attended the marathon events every 6 months. He said that he felt powerful and "released" after running. For another example, $\mathrm{M}$ did yoga in her apartment to pass time, which also helped her reduce stress. In short, participants developed new daily behaviors to seek help, to pass time, and to exercise for good physical and mental health.

\section{DISCUSSION AND CONCLUSIONS}

This qualitative study described the acculturation of East Asian graduate students in a Midwestern university from both socio-cultural and psychological adjustment perspectives. Specifically, these students have experienced challenges due to cultural differences, lack of support, and financial stress. Gradually, they have developed coping strategies of seeking external resources and employing self-adjustment. These challenges and coping strategies simultaneously impacted East Asian students' sociocultural adjustment and psychological adjustment. This finding was coincided with previous research that indicated that socio-cultural and psychological adjustments were closely interacted to each other (Ward, Okura, Kennedy, \& Kojima, 1998; Ward \& Kennedy, 1999).

Specially, challenges due to cultural differences was more related to these students' socio-cultural adjustment; while lack of support in a foreign environment and financial stress were more associated with students' psychological adjustment. Socio-cultural adjustment challenges included the factors that hindered East Asian graduate students' ability to fit in the new culture, to attain appropriate skills and to negotiate interactive areas of the host culture (Ward \& Kennedy, 1999). In this study, the socio-cultural adjustment challenges were found to include communication problems due to language issues, involvement problems due to socio-cultural differences, difficulties in learning due to academic differences, lack of academic support, and financial stress. The findings are consistent with previous research. East Asian students' acculturation challenges were mainly resulted by cultural distance in terms of difference language, religion, values, status, and race (Ward et al., 1998). Western cultural and East Asian cultures have a big cultural distance, such as individualism versus collectivism, language system differences, and academic system differences (Hofstede, 1984). Such 
great cultural distance indicates a more complicated adjustment process and more stress for East Asian students to adjust to the U.S. culture (Li et al., 2014; Mori, 2000). Among all the challenges, lack of academic support and financial stress put extra burdens on East Asian graduate students' sociocultural adjustment. According to Bronfenbrenner's (2009) ecological model of human development, the microsystem, which was the structure that an individual had direct contact, such as family, schools, and neighbors, had the greatest influence on the individual. When East Asian graduate students came to the U.S., they were far away from their families. Thus, their professors, school administrators, and colleagues become a microsystem to them and can easily influence their socio-cultural adjustment process. Accordingly, sufficient academic support from schools could help these students quickly adjust to the new academic system and the new culture. However, participants in this study reported a perceived lack of support from their departments, schools or their advisors. This finding is agreed with the previous research. Only $45 \%$ of the international students in a study by Chen and Yang (2014) recognized academic support from their departments and schools and most of those students stated that they had no clues where to seek help and who could be relied on to solve their difficulties. Moreover, most East Asian graduate students have to work on campus to support themselves financially. However, being a graduate assistant or teaching assistant means extra workload besides their already full coursework schedule, and the experience can be stressful (Zhou et al., 2011).

As the findings of the study indicated, problems in psychological adjustment came along with the aforementioned socio-cultural adjustment challenges. Psychological adjustment referred to psychological wellbeing or satisfaction (Ward \& Kennedy, 1996). "Frustration", "anger", and "stress" were the negative feelings that were related to the challenges due to language and academic differences. Students felt "marginalization" and "like an outsider" in classroom and social occasions due to the socio-cultural differences. Such findings were consistent with those of Ryan and Viete (2009) in which international students reported feeling like "outsiders" in classroom. Moreover, lack of academic support resulted in negative feelings such as stress, lack of direction, and frustration. Financial stress was reported as another significant challenge that impacted East Asian graduate students' mental health. The participants in this study reported a high degree of stress and worries related to assistant work and financial status that had 
negative influence on their mental health. In specific, guilty feelings stood out for the East Asian graduate students who still needed financial support from their family. Filial piety was one of the core values of Asian culture that meant children need to take care of their parents at a certain age (Young, 2017). It was especially hard to live up the expectations of filial piety for East Asian graduate students in the U.S. For those students, being at an age that they feel they should be financial independent but continued relying on their family for financial support, can be highly stressful.

Besides the psychological adjustment challenges coming with sociocultural adjustment, lack of emotional support impacted East Asian international students' psychological adjustment as well. This finding coincided with the statement of Ward and Kennedy (1996) that support systems impacted on psychological adjustment during acculturation: when people had a lower rate of support during acculturation, they experienced anxiety, depression, and helpfulness. Most of the East Asian international students reported a lack of emotional support from their American peers. Moreover, long-distance contact with families and old friends made them feel even lonely. The participants in the research stated that they attempted to make friends with American students but often failed. Such findings were consistent with the previous literature on international students. Fritz, Chin, and DeMarinis (2008) found that Asian international students reported it was harder to make new friends in the U.S. more often than European international students because of the cultural differences between East and West. Communication in Eastern Asian culture emphasize "process orientation, differentiated linguistic codes, indirect communication emphasis, and receiver-centered communication; while North American patterns of interaction often represent "outcome orientation, lessdifferentiated linguistic codes, direct communication emphasis, and sendercentered communication" (Yum, 1988, p. 374).

While few literature discussed the strategies to help with the above challenges, this study also explored the coping strategies. Students in the study mentioned that utilizing external resources for both socio-cultural and psychological adjustments. Among all the resources, help from their advisors was reported extremely useful, which was consistent with the previous research that good relationships with their advisors reduced international students' acculturative stress and improved their emotional well-being (Wei, Tsai, Chao, Du, \& Lin, 2012). Moreover, the peers from their home countries were reported to be helpful in both socio-cultural and 
psychological adjustments. The peers shared their own experience in the U.S. with the newcomers and provided personal suggestions for dealing with their challenges, however, their help may not be useful for the international students in the long run because they may develop dependency on the peers and then be lacking in their communication with American peers.

Another popular coping strategy reported by East Asian international students in this study was the development of self-adjustment skills that included behavioral and psychological adjustments. Behavioral self-adjustment strategies involved reaching out for help, working hard for academic achievement, and exercise for good health. Those behavioral adjustments not only helped with their socio-cultural adjustments but also benefited their psychological adjustments. Psychological self-adjustment strategies in this study referred to a cognitive reframing of stress-related problems and situations and forbearance. Szabo, Ward, and Jose (2015) also stated that the cognitive reframing was helpful to reduce people's stress level when they cannot change the environment. However, forbearance might be helpful in a short run but not in a long run, because it might be related to avoidance coping strategies (Wei, Liao, Heppner, Chao, \& Ku, 2012).

In summary, this paper explored the acculturation of East Asian graduate students that included their socio-cultural and psychological adjustments to American graduate education as well as their coping strategies. Students reported various challenges that interacted with their mental issues, which made the adaptation process even harder than previously imagined. Accordingly, we generated the following specific suggestions to the administrators, faculties, and school counselors who might be helpful for this population.

First, we recommend that administrators at different levels (department, college, and university) provide targeted support to East Asian international graduate students. For instance, international students' office director could schedule different orientation sessions on specific topics based on international graduates' original countries to meet different expectations they may have. Departments and schools should provide activities and opportunities for students to get involved with American students. Administrators should also be aware of students' financial needs and stress and give those students the opportunity to work on campus. Second, the advisors and supervisors of East Asian graduate students should 
learn to build cultural sensitivity when helping them adjust to the U.S. culture. Faculties can also encourage domestic students to help with East Asian students to learn about American culture and academics.

In addition to administrators, advisors, and supervisors who work with East Asian international graduate students, counseling services on the campus should address the stress of East Asian graduate students and provide them with culturally sensitive services and supports. Only one participant in the study mentioned counseling services as useful resources. However, counseling services could be a buffer of their stress during their acculturation process if counseling centers can provide culturally sensitive services (Li, Marbley, Bradley, \& Lan, 2016). For example, counselors can provide emotional support to students, help them to understand the differences between America and their home countries, and offer them some resources where they can seek help with their financial and language problems. According to Li et al. (2016), language and cultural differences were reported as their major concerns that prohibited their counseling seeking behavior, creative outreach programs that address their concerns should be employed by university counseling centers in order to provide support for East Asian international students (Hwang, Bennett, \& Beauchemin, 2014).

This research provided a new perspective to examine the acculturation of East Asian international students, but the contribution should be understood with the limitation of the research. The major limitation of the research was related to the number and representativeness of the participants. We had eight participants: four from Mainland China, two from South Korea, one from Taiwan, and one from Japan, and all of them are enrolled in a Midwestern university in the U.S. The proportion of the participants reflects the actual population of East Asian international students in the U.S. in which Chinese students represent the largest portion and South Korean, Taiwanese, and Japanese students come after Chinese students successively (IIE, 2017). However, their responses may not be generalized to other East Asian international graduate students, which is also the shortcoming of qualitative study (Creswell, 2012). Another limitation was that the investigators interviewed the Chinese participants in Chinese but using English with other participants. It might limit the information from the other participants other than Chinese ones. However, the PI's communication skills as a counselor and the validation strategy of member checking might reduce the influence of language barrier. 
In the future research, more participants should be recruited to get a more complete picture of all East Asian graduate students. Moreover, the diversity of participants should be included such as participants from different majors and schools. Moreover, interpreters of different East Asian languages may be employed to improve the communication in interviews. Last, future research should also consider the pre-arrival factors related to the acculturation difficulties and strategies, such as their personality, their language proficiency, and their coping styles.

\section{APPENDIX A}

\section{Code Table}

\begin{tabular}{|c|c|c|}
\hline Themes & Codes & Quotes \\
\hline \multirow[t]{6}{*}{$\begin{array}{l}\text { Challenges } \\
\text { due to cultural } \\
\text { differences }\end{array}$} & $\begin{array}{l}\text { Communication } \\
\text { problems due to } \\
\text { language issues }\end{array}$ & $\begin{array}{l}\text { I went to Verizon to change my phone plan and the } \\
\text { staff was very rude. I was very angry but I couldn't } \\
\text { even express my anger in English. I knew that I could } \\
\text { say anything if I were in Korea. I just went out of the } \\
\text { store and cried. }\end{array}$ \\
\hline & $\begin{array}{l}\text { Involvement } \\
\text { problems due to } \\
\text { socio-cultural } \\
\text { differences }\end{array}$ & $\begin{array}{l}\text { For most Chinese students, we believed that we should } \\
\text { have a comprehensive understanding before we could } \\
\text { have a talk in class; but American students are very } \\
\text { bold and say whatever come to their mind. }\end{array}$ \\
\hline & & $\begin{array}{l}\text { I felt awful that I could not be involved in their } \\
\text { conversation because of the different interests. I felt I } \\
\text { was so lonely even though I was around with people. }\end{array}$ \\
\hline & $\begin{array}{l}\text { Difficulties in } \\
\text { learning due to } \\
\text { academic }\end{array}$ & $\begin{array}{l}\text { I was almost immersed in the reading every day. } \\
\text { Teachers in my country often cover the reading } \\
\text { materials in class. }\end{array}$ \\
\hline & differences & $\begin{array}{l}\text { I chose two doctoral courses besides my masters } \\
\text { classes this semester. I found I was really stressed out. }\end{array}$ \\
\hline & & $\begin{array}{l}\text { I was so exhausted and I only could sleep for less than } \\
6 \text { hours a day in order to get my assignments done. }\end{array}$ \\
\hline \multirow{3}{*}{$\begin{array}{l}\text { Lack of } \\
\text { support in } \\
\text { foreign } \\
\text { environment }\end{array}$} & $\begin{array}{l}\text { Lack of academic } \\
\text { support }\end{array}$ & $\begin{array}{l}\text { There was no clear instruction about international } \\
\text { graduate students during my orientation. }\end{array}$ \\
\hline & & $\begin{array}{l}\text { My professor told me that he might fail my practicum } \\
\text { because of my language at the beginning of the } \\
\text { semester. It made me almost freaked out. I didn't } \\
\text { expect them to support me but at least did not give me } \\
\text { more pressure. }\end{array}$ \\
\hline & & $\begin{array}{l}\text { I got my undergraduate degree in the U.S., which can } \\
\text { already prove my English ability. Another TOFEL test }\end{array}$ \\
\hline
\end{tabular}




\begin{tabular}{|c|c|c|}
\hline Themes & Codes & Quotes \\
\hline & & $\begin{array}{l}\text { takes me extra time to prepare and seems not very } \\
\text { necessary. }\end{array}$ \\
\hline & & $\begin{array}{l}\text { I knew criticizing on my work would help me to } \\
\text { improve, but I wish that he could at least appreciate } \\
\text { what I have done. The extra work for him occupied my } \\
\text { personal time. }\end{array}$ \\
\hline & $\begin{array}{l}\text { Lack of } \\
\text { emotional support }\end{array}$ & $\begin{array}{l}\text { As graduate students, we diod not have time to get } \\
\text { together. I sometimes felt very lonely and depressed. }\end{array}$ \\
\hline & & $\begin{array}{l}\text { My parents did not understand what I am doing, but } \\
\text { urged me to go to work. I felt so depressed and } \\
\text { stressful when my significant others did not } \\
\text { understand my situation. }\end{array}$ \\
\hline \multirow{3}{*}{$\begin{array}{l}\text { Financial } \\
\text { stress }\end{array}$} & & I had to work for 20 hours a week to support myself. \\
\hline & & $\begin{array}{l}\text { I am } 30 \text { years old now. My classmates from college } \\
\text { have been working for so long. But I am still in school } \\
\text { and I had spent so much money to study abroad. This } \\
\text { guilty feeling may come from my own culture. I felt so } \\
\text { guilty to my girlfriend and family, I have no choice but } \\
\text { to work harder to get a better future. }\end{array}$ \\
\hline & & $\begin{array}{l}\text { During the time, I could not get financial support, I } \\
\text { felt stressful to meet my basic living needs. When I } \\
\text { went to a grocery tore, I sometimes think whether I } \\
\text { could afford it next time, even some small things. It's } \\
\text { hard to find jobs even though they are not related to } \\
\text { my major. When I am doing the job that is not related } \\
\text { to my major, I warned myself that I should go back to } \\
\text { my field as soon as possible, but I needed money. } \\
\text { Then, I questioned myself what I am doing here in the } \\
\text { U.S. Those questions made me crazy. }\end{array}$ \\
\hline \multirow[t]{3}{*}{$\begin{array}{l}\text { Utilizing } \\
\text { external } \\
\text { resources }\end{array}$} & $\begin{array}{l}\text { Resources for the } \\
\text { socio-cultural } \\
\text { adjustment }\end{array}$ & $\begin{array}{l}\text { Support from professors and advisors is so important, } \\
\text { because the professors are the people who have the } \\
\text { powet to change international students' life. }\end{array}$ \\
\hline & & $\begin{array}{l}\text { Students from China who had the same experience } \\
\text { ahead are very helpful, they helped me to open bank } \\
\text { account and drove me to the grocery stores. }\end{array}$ \\
\hline & $\begin{array}{l}\text { Resources for } \\
\text { psychological } \\
\text { adjustment }\end{array}$ & $\begin{array}{l}\text { The weekly TA group was very supportive. I remember } \\
\text { one time a TA said that he was so lonely. Another TA } \\
\text { came out and shared her own feeling of loneliness as } \\
\text { the oldest one in the group, and encouraged the TA } \\
\text { that there were lots of people with the same feeling. I } \\
\text { felt so involved and supported even though I was not } \\
\text { the guy who came up with the question. }\end{array}$ \\
\hline
\end{tabular}




\begin{tabular}{|c|c|c|}
\hline Themes & Codes & Quotes \\
\hline & & $\begin{array}{l}\text { I skyped with my old friends in Japan almost every day } \\
\text { in my first year in the U.S., which gave me tons of } \\
\text { emotional support. }\end{array}$ \\
\hline & & $\begin{array}{l}\text { I went to the counseling center in our school to get } \\
\text { help when I could not find anyone to talk with. }\end{array}$ \\
\hline \multirow{5}{*}{$\begin{array}{l}\text { Developing } \\
\text { self- } \\
\text { adjustment } \\
\text { strategies }\end{array}$} & \multirow{2}{*}{$\begin{array}{l}\text { Psychological } \\
\text { self-adjustment } \\
\text { strategies }\end{array}$} & $\begin{array}{l}\text { Sometimes I just wanted to quit, but my dream kept me } \\
\text { to stay here. }\end{array}$ \\
\hline & & $\begin{array}{l}\text { When I felt that I couldn't do anything about my } \\
\text { difficulties, I told myself that the only thing I can do is } \\
\text { to let it go. It takes time and not easy, but that is the } \\
\text { only way I can do. }\end{array}$ \\
\hline & \multirow[t]{3}{*}{$\begin{array}{l}\text { Behavioral self- } \\
\text { adjustment } \\
\text { strategies }\end{array}$} & $\begin{array}{l}\text { Before I came here, I seldom reach out for help from } \\
\text { my teachers. But now I look forward to meeting with } \\
\text { my professors and ask for suggestions when I met } \\
\text { difficulties. }\end{array}$ \\
\hline & & $\begin{array}{l}\text { I tried to catch every change to know more about their } \\
\text { culture and system because I know it is the best way to } \\
\text { be involved in their society. }\end{array}$ \\
\hline & & $\begin{array}{l}\text { I regularly ran for } 10 \text { miles for a week and attended } \\
\text { the marathon events around our university. I felt much } \\
\text { released after running. }\end{array}$ \\
\hline
\end{tabular}

\section{REFERENCES}

Baruth, L. G., \& Manning, M. L. (2007). Multicultural counseling and psychotherapy: a lifespan perspective. Upper Saddle River, NJ: Pearson/Merrill Prentice Hall.

Berry, J. W., Poortinga, Y. H., Breugelmans, S. M., Chasiotis, A., \& Sam, D. L. (2011). Cross-cultural Psychology: Research and Applications. Cambridge, UK: Cambridge University Press.

Bertram, D. M., Poulakis, M., Elsasser, B. S., \& Kumar, E. (2014). Social support and acculturation in Chinese international students. Journal of Multicultural Counseling \& Development, 42(2), 107-124.

Bronfenbrenner, U. (2009). The ecology of human development. Cambridge, MA: Harvard University Press.

Brunette, M. K., Lariviere, M., Schinke, R. J., Xing, X., \& Pickard, P. (2011). Fit to belong: Activity and acculturation of Chinese students. Journal of Sport Behavior, 34(3), 207-227. 
Chen, D., \& Yang, X. (2014). Striving and thriving in a foreign culture: A mixed method approach on adult international students' experience in U.S.A. Journal of Education and Training Studies, 2(3), 16-25.

Creswell, J. W. (2012). Educational research: planning, conducting, and evaluating quantitative and qualitative research. Boston: Pearson.

Fritz, M. V., Chin, D., \& DeMarinis, V. (2008). Stressors, anxiety, acculturation and adjustment among international and North American students. International Journal of Intercultural Relations, 32(3), 244-259.

Han, X., Han, X., Luo, Q., Jacobs, S., \& Jean-Baptiste, M. (2013). Report of a mental health survey among Chinese international students at Yale University. Journal of American College Health, 61(1), 1-8.

Hofstede, G. H. (1984). Culture's consequences, international differences in workrelated values. Beverly Hills, CA: Sage Publications.

Hwang, B. J., Bennett, R., \& Beauchemin, J. (2014). International students' utilization of counseling services. College Student Journal, 48(3), 347354.

Institute of International Education. (2017). Open Doors 2017 Report. Retrieved March 25, 2018, from https://www.iie.org/Research-and-Insights/OpenDoors/Data/International-Students/Places-of-Origin

Kim, Y. Y. (1988). Communication and cross-cultural adaptation: An integrative theory. Philadelphia: Multilingual Matters.

Li, J., Marbley, A. F., Bradley, L. J., \& Lan, W. (2016). Attitudes toward seeking professional counseling services among Chinese international students: Acculturation, ethnic identity, and English proficiency. Journal of Multicultural Counseling \& Development, 44(1), 65-76.

Li, J., Wang, Y., \& Xiao, F. (2014). East Asian international students and psychological well-being: A systematic review. Journal of International Students, 4(4), 301-313.

Lindlof, T. R., \& Taylor, B. C. (2010). Qualitative communication research methods. Los Angeles: Sage Publications.

Liu, M. (2009). Addressing the mental health problems of Chinese international college students in the United States. Advances in Social Work, 10(1), 6986.

Mori, S. C. (2000). Addressing the mental health concerns of international students. Journal of Counseling \& Development, 78(2), 137-144.

Oswalt, S. B., \& Riddock, C. C. (2007). What to do about being overwhelmed: Graduate students, stress and university services. College Student Affairs Journal, 27(1), 24-44.

Park, H., Lee, M.-J., Choi, G.-Y., \& Zepernick, J. S. (2017). Challenges and coping strategies of East Asian graduate students in the United States. International Social Work, 60(3), 733-749. 
Ra, Y.-A., \& Trusty, J. (2017). Impact of social support and coping on acculturation and acculturative stress of East Asian international students. Journal of Multicultural Counseling and Development, 45(4), 276-291.

Redfield, R., Linton, R., \& Herskovits, M. J. (1936). Memorandum for the Study of Acculturation. American Anthropologist, 38(1), 149-152.

Reischauer, E. O. (1974). The Sinic World in Perspective. Foreign Affairs, 52(2), 341-348.

Ryan, J., \& Viete, R. (2009). Respectful interactions: learning with international students in the English-speaking academy. Teaching in Higher Education, 14(3), 303-314.

Strauss, A., \& Corbin, J. (1990). Basics of qualitative research. Newbury Park, CA: Sage Publications.

Szabo, A., Ward, C., \& Jose, P. E. (2015). Uprooting stress, coping, and anxiety: A longitudinal study of international students. International Journal of Stress Management, 23(2),190-208.

United Nations Educational, Scientific and Cultural Organization. (2006). UNESCO Institute for Statistics' (UIS) global education digest. Retrieved May 4, 2017, from http://www.wpunj.edu/cie/definition-of-internationalstudent.html

Ward, C., \& Kennedy, A. (1996). Crossing cultures: The relationship between psychological and socio-cultural dimensions of cross-cultural adjustment. In J. Pandey, D. Sinha, D. P. S. Bhawuk, J., Pandey, D., Sinha, \& D. P. S., \& Bhawuk (Eds.), Asian contributions to cross-cultural psychology (pp. 289-306). Thousand Oaks, CA: Sage Publications.

Ward, C., \& Kennedy, A. (1999). The measurement of sociocultural adaptation. International Journal of Intercultural Relations, 23, 659-677.

Ward, C., Okura, Y., Kennedy, A., \& Kojima, T. (1998). The U-Curve on trial: a longitudinal study of psychological and sociocultural adjustment during Cross-Cultural transition. International Journal of Intercultural Relations, 22(3), 277-291.

Wei, M., Liao, K. Y.-H., Heppner, P. P., Chao, R. C.-L., \& Ku, T.-Y. (2012). Forbearance coping, identification with heritage culture, acculturative stress, and psychological distress among Chinese international students. Journal of Counseling Psychology, 59(1), 97-106.

Wei, M., Tsai, P.-C., Chao, R. C.-L., Du, Y., \& Lin, S.-P. (2012). Advisory working alliance, perceived English proficiency, and acculturative stress. Journal of Counseling Psychology, 59(3), 437-448.

Ye, J. (2005). Acculturative stress and use of the Internet among East Asian international students in the United States. Cyberpsychology \& Behavior: The Impact of The Internet, Multimedia and Virtual Reality On Behavior And Society, 8(2), 154-161. 
Young, J. T. (2017). Confucianism and accents: Understanding the plight of the Asian international student in the U.S. Journal of International Students, 7(3), 433-448.

Yum, J. O. (1988). The impact of Confucianism on interpersonal relationships and communication patterns in east Asia. Communication Monographs, 55(4), 374-388.

Zhang, J., \& Goodson, P. (2011). Predictors of international students' psychosocial adjustment to life in the United States: A systematic review. International Journal of Intercultural Relations, 35(2), 139-162.

Zhou, Y., Frey, C., \& Bang, H. (2011). Understanding of international graduate students' academic adaptation to a U.S. graduate school. International Education, 41(1), 76-94.

YIYING XIONG is a doctoral candidate from Department of Counseling and Higher Education in Ohio University. She is interested in acculturation issues and mental health of Asian international students. Email: yx206714@ohio.edu

YUCHUN ZHOU is an assistant professor in the Educational Research and Evaluation program in Ohio University. She holds the Ph.D. in research methodology from The University of Nebraska-Lincoln. Her major research interests include measurement in education, longitudinal research and multilevel modeling, latent trait measurement models, structural equation modeling, and mixed methods research. She teaches the courses of Research Designs, Test Theory and Measurement, and Qualitative Research. Email: zhouy@ohio.edu 